\title{
An empirical study on the trend of students' academic achievement in Fujian and Taiwan cooperative universities
}

\author{
Weixia Liu',2,a , Yanfang Zhu ${ }^{1, b}$ and Xiaoqing Yan ${ }^{1,2, c}$ \\ ${ }^{1}$ Straits Institute of Minjiang University, Fuzhou,350108, Fujian, China \\ ${ }^{2}$ Institute of Cross-Strait Higher Education Cooperation and Exchange, Fuzhou,350108, Fujian, \\ China \\ aliuweixia0201@126.com, b770152491@qq.com, c380158915@qq.com
}

Key words: Fujian-Taiwan cooperative education, Academic Achievement, Changing Trend.

\begin{abstract}
Based on the four-year academic scores of selected undergraduates from a Fujian-Taiwan cooperative university, this paper analyzes the trend of college students' academic performance, as well as the gender differences and urban-rural differences. Key findings are summarized as follows: first, college students' academic performance is a "rise-fall-rise" process as a whole. the female students' performance is better than the male students'. The highest point of students' performance occurs in the fifth semester, and the lowest point occurs in the seventh semester. Third, urban and rural areas have no significant impact on students' performance. The findings may provide references for China's universities in enhancing educational governance and improving educational quality, thereby promoting the development of a powerful nation in higher education.
\end{abstract}

\author{
闽台合作办学大学生学习成绩变化趋势的实证研究 \\ 刘伟霞 $1,2, \mathrm{a}$ ，朱艳芳 $1, \mathrm{~b}$, 颜小清 $1,2, \mathrm{c}$ \\ 1 闽江学院海峡学院, 福州, 福建, 中国 \\ 2海峡两岸高等教育合作与交流研究所, 福州, 福建, 中国 \\ aliuweixia0201@126.com, b770152491@qq.com, c380158915@qq.com
}

关键词：闽台合作办学；学习成绩；变化趋势

中文摘要. 本文使用某闽台合作高校大学生四年的成绩数据, 分析了大学生学习成绩的变化 趋势, 以及这种趋势的性别差异和城乡差异。结果发现: 第一, 大学生学习成绩在总体上表 现为一个“升-降-升”的过程。第二, 八个学期中女生成绩都比男生成绩优秀, 男生和女生成绩 的最高点度出现在第五学期, 男生和女生成绩的最低点均出现在第七学期。第三, 城乡对学 生的成绩没有显著影响。研究结论有助于提高教育管理者工作的针对性和有效性, 提升大学 教育教学水平, 助推高等教育强国建设。

\section{1. 引言}

如何引入实质性的教育变革, 提高教育质量, 一直是教育规划者们关注的问题。这种对 质量的关注逐渐从学习成果的投入转移到了学习成绩。自1999年大学扩招政策实施以来, 我 国高等教育的规模迅速扩大, 实现了由精英教育向大众化教育的过渡, 高等教育改革和发展 的重点也因此转向“提高教育质量”。 
丰富的资源和良好的环境为闽台合作办学提供了良好的外部条件，然而由于两岸高校在 教育理念、内部运行机制等方面存在差异, 在高校管理的有效性、学生的素质培养方面仍处 于探索阶段, 对闽台合作办学的学生培养内容、培养模式及其质量的评价仍相对薄弱。学生 是高等教育的主体, 获取知识又是大学生的基本任务。因此, 大学生学习成绩的好坏历来都 是评价和衡量教育质量的重要指标之一, 也是教育主管部门对教学水平进行考核的主要依据。 关注大学生学习成绩也成为教育学和社会学等领域的经典研究方向。

因此, 本文拟从闽台合作办学学生培养质量的视角出发, 借助福建某二本高校学生在本 科四年中的成绩数据, 对大学生学习成绩变化趋势及其影响因素做初步的分析和思考。本研 究的主要目的有两个: 一方面, 考察大学生学习成绩在本科四年间的变化情况, 以明晰其发 展趋势, 从而对大学生学习成绩变化情况有一个总体的认识; 另一方面, 考察性别和出生户 籍这种社会属性特征对大学生学习成绩变化趋势的影响, 从而为高校教育管理者提供参考, 增强工作的针对性和有效性, 不断提高大学教育质量和教育水平。

\section{2. 研究方法}

\section{1 数据}

本研究使用福建省某二本高校2013级闽台合作办学本科生的大学成绩数据进行分析。闽 台合作办学采取“ $3+0$ ”模式, 即大一、二在本校学习, 大三赴台湾合作高校学习, 大四回到本 校学习。由于大学的学习考核是按学期进行的, 所以每个学生均有 8 个学习成绩观测值。每个 观测值的间隔均为半年。还从学校的资料数据中选取了这部分学生的一些变量信息, 如性别、 户籍等。样本数据共包括 1076 名本科生。其中, 男生占比 $33.6 \%$, 女生占比为 $66.4 \%$; 城市户 籍占比为 $59 \%$, 农村户籍占比为 $41 \%$ 。

\section{2 变量与测量}

本研究是按学期成绩进行分析。每个学期学习成绩的计算方式如下: 首先, 用学生在该 学期所修的每门课成绩乘上该课程对应的学分, 得到每门课的加权成绩; 然后, 把所修全部 课程的加权成绩相加, 得到学生的加总成绩; 最后, 用学生的加总成绩除以该学生在相应学 期所修课程学分的加总。每个学生的成绩在0-100这个量纲上。比如, 学生小明在第一学期共 修了 $\mathrm{A} 、 \mathrm{~B} 、 \mathrm{C}$ 三门课程, 他的每门课程考试成绩分别是 82 分、75分、93分, 这三门课程的学 分分别是 1 分、 2 分、 4 分, 课程满分成绩均为 100 分。那么, 学生小明在第一学期的学习成绩 为 $(82 * 1+75 * 2+93 * 4) /(1+2+4)=86.29$ 分。

研究大学生学习成绩的变化趋势, 学期是本文的关键自变量, 取值为 $1-8$ 。性别和户籍是 本研究关注的两个影响因素变量。男生编码为 1 , 女生编码为 2 ; 城市户口编码为 1 , 农村户口 编码为 2 。

\section{3. 分析结果}

表1是大学生各学期学习成绩的均值与中位值。从平均数中可以看出, 大学生学习成绩出 现了 “三个高点” 和“两个低点”。三个高点分别是第五学期83.97分、第六学期83.7分和第八学 期81.01分; 两个低点是第二学期75.68分和第七学期78.08分。而各学期学习成绩的中位值虽 和均值略有差异, 但总体变化趋势一致。这说明, 一些极端值并不会对学生成绩的变化趋势 分析造成实质性的影响。图1是对表1的直观反映。我们可以很明显地观察到, 两个数值均呈 现出一种“升-降-升”的形态。 
表1大学生学习成绩总趋势分析

\begin{tabular}{|c|c|c|c|c|c|c|c|c|}
\hline 学期 & 1 & 2 & 3 & 4 & 5 & 6 & 7 & 8 \\
\hline 均值 & 76.40 & 75.68 & 77.58 & 78.67 & 83.97 & 83.70 & 78.08 & 81.01 \\
\hline 中位值 & 77.02 & 76.47 & 78.78 & 79.98 & 84.38 & 84.25 & 80.00 & 83.00 \\
\hline
\end{tabular}

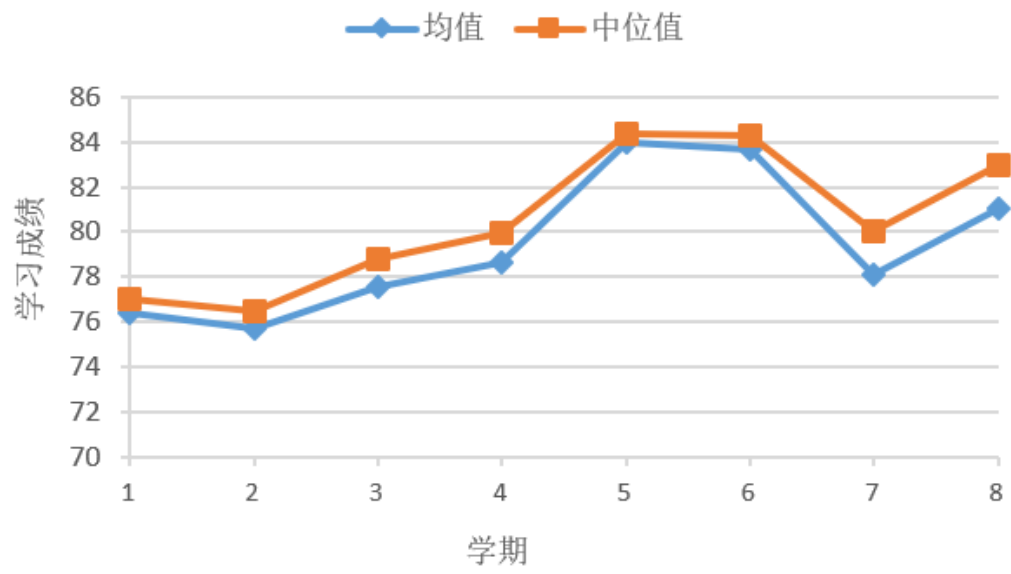

图 1 大学生学习成绩变化趋势图

表2将样本分成城市男生、农村男生、城市女生、农村女生四类，并计算出这四类群体在 各个学期的均值和中位值。图2和图3分别是对表2的图像反映。显然, 这四类群体的学习成绩 变化趋势与总体趋势大体一致。

表2 大学生学习成绩的性别、城乡交互分析

\begin{tabular}{|c|c|c|c|c|c|c|c|c|}
\hline \multirow{2}{*}{ 学期 } & \multicolumn{2}{|c|}{ 城市男生 } & \multicolumn{2}{c|}{ 农村男生 } & \multicolumn{2}{c|}{ 城市女生 } & \multicolumn{2}{c|}{ 农村女生 } \\
\cline { 2 - 9 } & 均值 & 中位值 & 均值 & 中位值 & 均值 & 中位值 & 均值 & 中位值 \\
\hline 1 & 74.40 & 75.33 & 73.73 & 74.35 & 77.42 & 77.88 & 77.76 & 78.44 \\
\hline 2 & 72.94 & 73.33 & 73.20 & 73.87 & 76.72 & 77.20 & 77.44 & 78.42 \\
\hline 3 & 74.58 & 75.78 & 74.61 & 76.16 & 78.69 & 79.66 & 79.70 & 80.20 \\
\hline 4 & 75.17 & 76.84 & 75.42 & 77.38 & 79.98 & 80.91 & 80.99 & 81.63 \\
\hline 5 & 81.69 & 82.10 & 82.03 & 82.16 & 84.65 & 84.96 & 85.68 & 86.08 \\
\hline 6 & 81.71 & 81.85 & 82.38 & 82.44 & 84.01 & 84.68 & 85.42 & 85.86 \\
\hline 7 & 73.45 & 77.00 & 75.37 & 78.04 & 79.78 & 80.75 & 80.31 & 81.25 \\
\hline 8 & 78.75 & 82.09 & 78.82 & 81.91 & 81.67 & 83.00 & 82.88 & 83.00 \\
\hline
\end{tabular}




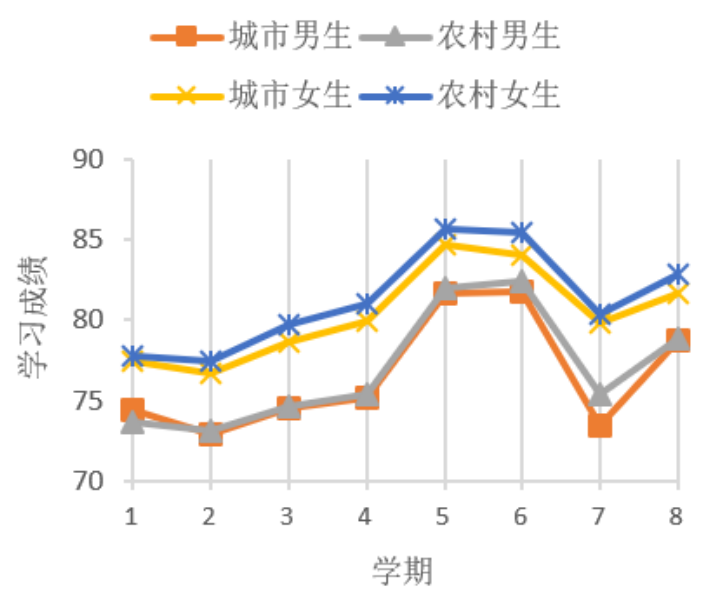

图2 大学生学习情况变化趋势（均值）

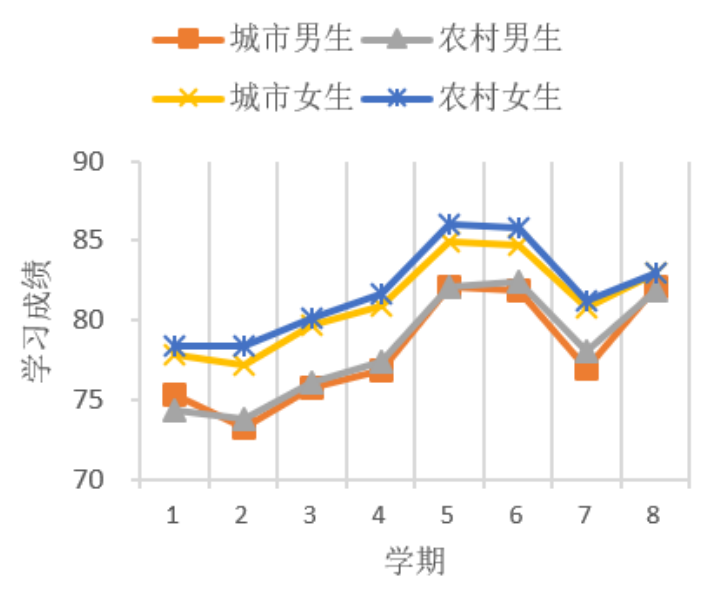

图3 大学生学习情况变化趋势（中位值）

表3是对不同群体学生学习成绩的性别、城乡差异分析。研究结果表明, 女生学习成绩的 水平显著高于男生 ( F值为 212.074 , 显著性水平 $<0.001$ ) ; 而城市与农村的学生学习成绩水平 并没有明显差异（ $\mathrm{F}$ 值为 3.072 , 显著性水平为 0.080 )。

表3 大学生学习成绩起始水平的性别、城乡差异检验

\begin{tabular}{|c|c|c|c|}
\hline 变量 & 均值 & F值 & Sig \\
\hline \multicolumn{4}{|l|}{ 性别差异 } \\
\hline 男性学生 & 76.75 & 212.074 & $<0.001$ \\
\hline 女性学生 & 80.72 & & \\
\hline 城乡差异 & \multicolumn{2}{l|}{} \\
\hline 城市学生 & 76.18 & 3.072 & 0.080 \\
\hline 农村学生 & 79.68 & & \\
\hline
\end{tabular}

\section{4. 结束语}

本研究使用某闽台合作办学高校2013级大学生的管理数据, 对其进行了大学生学习成绩 变化趋势的分析。研究分析, 大学生学习成绩总体上呈现出“升-降-升”的形态, 从整体上看, 学生在第三学年成绩较优异, 第一学年成绩较低。与以往认为大学生学习成绩是先下降后上 升的结论不太相同。原因有两个, 首先大一时因为刚刚从高考紧张的氛围中脱离出来, 又加 之大学的学习环境、方式等与初高中不太一样, 导致大学生们刚开始找不到适合自己的学习 方法, 致使初入大学校园时成绩不太理想。另外, 可能是学生大三在台湾合作高校学习, 环 境不熟悉并且学习机会难得, 学生学习比较刻苦。在引入性别与户籍两个变量之后, 这种趋 势仍然保持不变, 但是男生学习成绩普遍低于女生。从上述的研究来看, 大学教育工作者应 该要特别注重刚入学的新生们, 帮助并引导他们地找到适合自身的学习方法, 以便快速地适 应大学的学习生活, 从而提高大学教育的起始水平。在城乡差异的检验中, 我们发现其实城 市与农村的学生学习成绩并无明显的差别, 这与普遍认为农村的教学水平大大落后于城市, 以致农村统招的大学新生成绩会落后于城市学生的观点不太相同。因为该校闽台合作办学生 源绝大部分来自福建省, 当地民营经济活跃, 城乡没有显著差异。需要注意的是, 大学成绩 存在显著的性别差异, 女生的成绩高于男生。基于这点, 教师应充分利用各种教学手段和方 法调动男生的学习热情, 培养他们主动学习、独立分析和解决实际问题的能力。 


\section{致谢}

本文为国家职业教育研究院福建分院研究项目《职业教育对闽台经济增长影响的比较研 究》(GZM14005)的阶段性成果之一。

\section{References}

[1] Xiao-Juan Q, Xiao-Wen Z, The Changing Trend in College Students' Academic Achievement and Its Influential Factors: An Empirical Analysis, Fudan Education Forum, vol.14, pp. 45-51, 2016.

[2] David L T, Academic Cheating in College Students: Relations among Personal Values, Self-esteem and Mastery, Procedia - Social and Behavioral Sciences, vol.187, pp.88-92, 2015.

[3] Rongbo T, Huaqing C, Analysis of the Difference Existed in the Academic Records between Urban Students and Rural Students from Local Universities, Shanghai Journal of Educational Evaluation, vol.4, pp. 25-28+44, 2015.

[4] Hamid B, Nursing Students' Perceptions of their Educational Environment Based on DREEM Model in an Iranian University, Malaysian Journal of Medical Sciences, vol.20, pp. 56-63, 2013.

[5] Zhou Y, Sang Q, Ge M, A Study on the Relations of College Students' Self-Regulated Learning and Achievement Goal Orientation with Academic Achievement, Psychological Science, vol.33, pp. 194-197, 2010. 